\title{
STUDI RESPON DAERAH ALIRAN SUNGAI CIMANYAR TERHADAP BERBAGAI KEJADIAN HUJAN
}

\author{
Fuad Hasan ${ }^{1}$, Bambang Eko Widyanto ${ }^{2}$, R.H.B. Ash Siddiq ${ }^{3}$ \\ Program Studi Teknik Sipil ${ }^{1,2,3}$ \\ Universitas Widyatama \\ Jalan Cikutra noo 204A, Cikutra, Kota Bandung \\ hasan.fuad@widyatama.ac.id ${ }^{1}$, bambang.widyanto@widyatama.ac.id ${ }^{2}$, \\ raden.herdian@widyatama.ac.id ${ }^{3}$
}

\begin{abstract}
Abstrak
Daerah Aliran Sungai (DAS) Cimanyar merupakan salah satu Sub DAS Cimanuk. Pada DAS ini terdapat stasiun pencatatan hujan dan debit dengan durasi jam-jaman. Berdasarkan data yang diperoleh dilapangan terdapat perbedaan respon DAS yang cukup signifikan. Hidrograf kejadian hujan pada tanggal 4 Februari 2013 memperlihatkan adanya limpasan permukaan pada DAS tersebut. Sedangkan hidrograf kejadian hujan pada tanggal 27 Oktober 2012 mengindikasikan adanya mekanisme aliran bawah permukaan (interflow). Untuk melihat respon DAS tersebut maka pada studi ini dikembangkan model hidrologi dengan MIKE SHE yang terkalibrasi dan tervalidasi dengan debit pengukuran di stasiun pengamatan Cimanyar.
\end{abstract}

Kata kunci : Daerah Aliran Sungai, Hidrograf, MIKE SHE

\begin{abstract}
The Cimanyar River Basin is one of the Cimanuk watersheds. There is a rain and debit recording station with the duration of hours. Based on the data obtained in the field there is a significant difference in the watershed response. The hydrograph of the rainfall event on February 4, 2013 shows the surface runoff in the watershed. While the hydrograph of rainfall events on 27 October 2012 indicates the existence of a subsurface flow mechanism (interflow). To see the watershed response, this study developed a hydrological model with MIKE SHE which was calibrated and validated with measurement discharges at the Cimanyar observation station.
\end{abstract}

Keywords: Watershed, Hydrograph, MIKE SHE

\section{Pendahuluan}

Daerah Aliran Sungai (DAS) Cimanyar merupakan salah satu Sub DAS Cimanuk. Pada DAS Cimanyar ini terdapat 9 anak sungai yang bermuara ke sungai Cimanuk, yaitu Cimanuk Hulu, Cipanyingkiran, Ciroyom, Cibuluh, Cimaja, Cidawa, Cileteuy dan Cihideung. DAS Cimanyar yang memiliki luas mencapai $31 \mathrm{~km}^{2}$ ini terdapat stasiun pencatatan hujan dan debit dengan durasi jam-jaman. Berdasarkan data yang diperoleh dilapangan terdapat perbedaan respon DAS yang cukup signifikan. Hidrograf kejadian hujan pada tanggal 4 Februari 2013 memperlihatkan adanya limpasan permukaan pada DAS tersebut. Sedangkan hidrograf kejadian hujan pada tanggal 27 Oktober 2012 mengindikasikan adanya mekanisme aliran bawah permukaan (interflow).

Untuk melihat kejadian hidrologis pada DAS Cimanyar, penulis akan melakukan pemodelan hidrologi yang akan dibantu dengan menggunakan software MIKE SHE untuk pemodelan overland flow serta sofware MIKE 11 untuk pemodelan hidrolika di sungai. Setelah itu kemudian dilakukan kombinasi antara MIKE SHE dan MIKE 11 untuk mengetahui dan menganalisis kejadian hidrologis yang terjadi di DAS Cimanyar. 


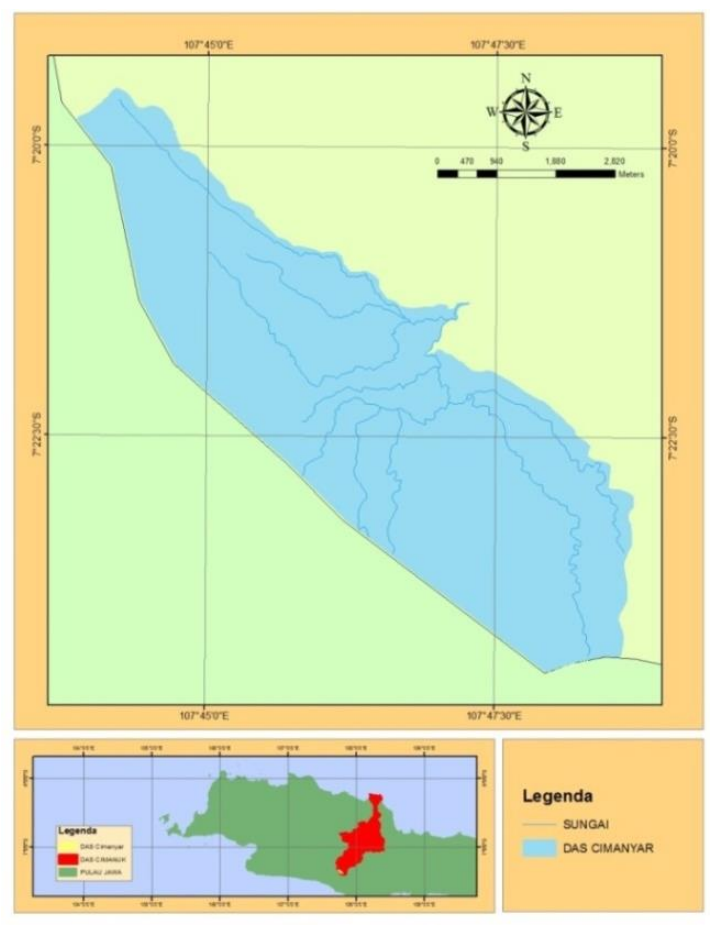

Gambar 1. DAS Cimanyar

\section{KAJIAN LITERATUR}

\section{II.1 Hidrograf}

Hidrograf adalah kurva yang memberi hubungan antara parameter aliran dan waktu. Parameter tersebut dapat berupa kedalaman aliran (elevasi) atau debit aliran, sehingga terdapat dua macam hidrograf muka air dan hidrograf debit. Hidrograf muka air dapat ditransformasikan menjadi hidrograf debit dengan menggunakan rating curve.

Suatu hidrograf dapat dianggap sebagai suatu gambaran dari karakteristik fisiografis dan klimatis yang mengendalikan hubungan antara curah hujan dan pengaliran dari suatu DAS tertentu. Komponen yang merupakan sumber penyebab aliran di sungai antara lain; air yang berasal langsung dari hujan (precipitation), limpasan permukaan (surface runoff), aliran bawah tanah (subsurface flow, interflow) dan aliran air tanah (groundwater flow), (Chow, 1964 dalam Sri Harto (1993).

Hidrograf aliran terdiri dari tiga komponen, yaitu: (1) sisi naik (rising limb), (2) bagian puncak (crest), (3) sisi resesi (recession limb) sebagai ditunjukkan pada Gambar 2. Sisi naik menandakan masih adanya kontribusi hujan terhadap debit aliran. Puncak hidrograf adalah debit maksimum yang terjadi dalam suatu aliran dengan waktu naik yang merupakan selang waktu antara mulai bertambahnya aliran sampai tercapainya debit puncak. Sisi turun merupakan proses pengatusan daerah tangkapan. Waktu dasar yaitu waktu mulai bertambahnya debit aliran sampai kembali ke debit aliran dasar. Hidrograf tersebut adalah hidrograf tunggal yang dihasilkan oleh hujan periode tunggal, sedang hidrograf kompleks yang mempunyai puncak ganda atau lebih merupakan aliran dari hujan periode panjang dengan intensitas yang bervariasi.

Hidrograf aliran sungai adalah sebuah grafik yang menunjukkan hubungan antara debit aliran sungai sebagai fungsi waktu pada titik tertentu di aliran sungai. Hidrograf aliran sungai menunjukkan hubungan antara karakteristik fisiografis sungai dan karakteristik aliran limpasan pada suatu DAS/daerah tangkapan (Chow, 1959 dalam Chow, Maidmet dan Mays, 1988). Hidrograf aliran sungai dibagi menjadi dua macam yaitu hidrograf tahunan yang menunjukkan debit aliran sebagai fungsi waktu dalam kurun waktu tahun dan hidrograf hujan yang menunjukkan debit aliran sebagai akibat dari satu kejadian hujan.

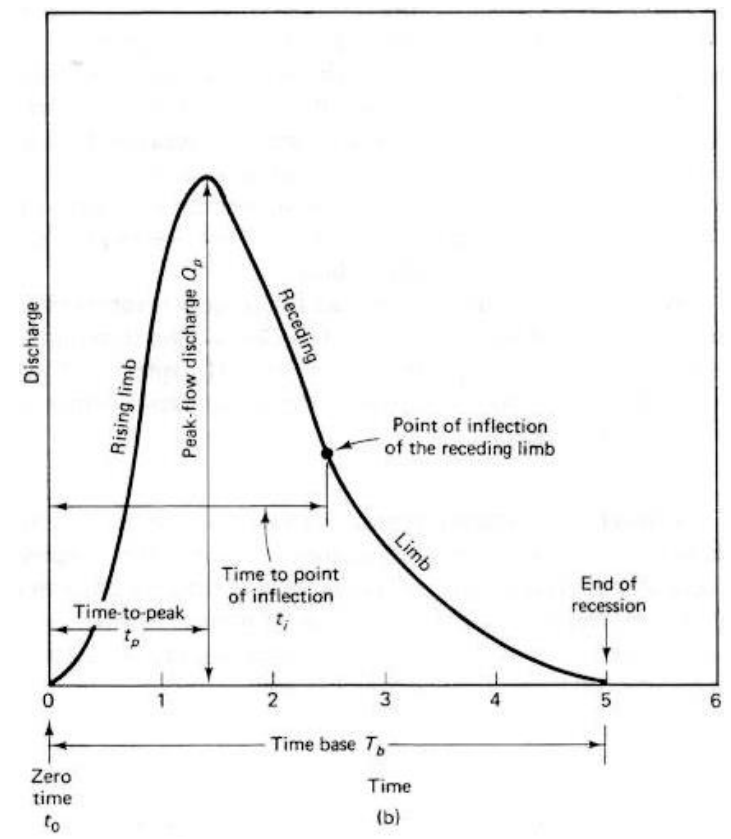

Gambar 2. Komponen Hidrograf (Ponce, 1989)

\section{II.2 Pemodelan MIKE SHE}

MIKE SHE merupakan salah satu software untuk pemodelan hidrologi yang dikembangkan oleh DHI Water and Environment Denmark. Dalam MIKE SHE ini terbagi menjadi 4 bagian yaitu Overland Flow, Evapotranspirasi, Unsaturated Flow dan Saturated Zone. 


\section{II.3 Evaluasi Hasil Model}

Pemodelan yang telah dilakukan dan telah dikalibrasi perlu dicek kesesuaiannya. Untuk mengecek kesesuaian hasil pemodelan yang telah dilakukan dengan data pengamatan yang ada, maka perlu dilakukan kalibrasi. Tujuan dari kalibrasi ini adalah untuk menentukan nilai sekelompok parameter, sehingga hasil simulasi debit oleh model mendekati nilai debit yang sebenarnya. Kriteria yang digunakan untuk evaluasi kemampuan model yang digunakan yaitu Nash Sutcliffe Efficiency (NSE) (Tanika, 2013). NSE atau koefisien Nash dihitung berdasarkan persamaan di bawah ini.

$$
N S E=1-\frac{\sum_{t}\left({ }^{O b s_{i, t}}-\operatorname{Calc}_{i, t}\right)^{2}}{\sum_{t}\left(\mathrm{Obs}_{i, t}-\overline{\mathrm{Obs}}_{i, t}\right)^{2}}
$$

NSE menunjukkan tingkat ketelitian dari korelasi hubungan antara data yang terukur dan terhitung. Fungsi ini digunakan untuk mengevaluasi kesahihan model. Sebuah model yang bagus akan menghasilkan nilai koefisien Nash mendekati $1 \quad(0<\mathrm{N}<1)$ (Indarto, 2010).

\section{Metodologi}

Metodologi yang digunakan dalam penelitian ini adalah:

- Studi literatur penelitian terdahulu

- Pengumpulan data

- Membuat model hidrologi

- Kalibrasi dan validasi data

\section{Analisis dan Pembahasan}

\section{IV.1 Analisa Hujan}

Pada penelitian ini, data yang digunakan dalam analisa hujan adalah data hujan jam-jaman maupun harian yang tercatat di stasiun-stasiun pada DAS Cimanyar dari bulan September 2012 hingga Juli 2013. Data hujan jam-jaman yang tersedia pada DAS Cimanyar hanya ada pada stasiun hujan Cimanyar saja. Oleh karena itu untuk menentukan curah hujan pada stasiun lainnya dilakukan dengan cara menurunkan curah hujan harian ke jam-jaman. Data hujan jamjaman pada stasiun Cimanyar dianalisa prosentase distribusinya selama durasi yang terjadi. Prosentase distribusi yang diperoleh dari perhitungan tersebut dapat digunakan untuk menurunkan data hujan harian di stasiun lainnya. Proses penurunan data hujan dilakukan dengan melihat kejadian hujan pada waktu yang sama.
Tabel 1. Data Stasiun Cimanyar dan Ciharus

a. Kejadian hujan 1 (4 februari 2013)

\begin{tabular}{|c|c|c|c|c|}
\hline \multirow{2}{*}{ Hour } & \multicolumn{3}{|c|}{ Rainfall (mm) } & \multirow{2}{*}{$\begin{array}{c}\text { Observed } \\
\text { Discharge }(\mathrm{m} 3 / \mathrm{s})\end{array}$} \\
\hline & Cimanyar & Ciharus & $\mathrm{R}_{\text {region }}$ & \\
\hline 1 & 0.50 & 1.02 & 0.64 & 0.00 \\
\hline 2 & 7.50 & 15.27 & 9.65 & 0.00 \\
\hline 3 & 5.50 & 11.19 & 7.08 & 8.16 \\
\hline 4 & 0.00 & 0.00 & 0.00 & 8.78 \\
\hline 5 & 0.00 & 0.00 & 0.00 & 7.64 \\
\hline 6 & 0.00 & 0.00 & 0.00 & 0.52 \\
\hline
\end{tabular}

b. Kejadian Hujan 2 (27 september 2012)

\begin{tabular}{|c|c|c|c|c|}
\hline \multirow{2}{*}{ Hour } & \multicolumn{3}{|c|}{ Rainfall (mm) } & \multirow{2}{*}{$\begin{array}{c}\text { Observed } \\
\text { Discharge }(\mathrm{m} 3 / \mathrm{s})\end{array}$} \\
\cline { 2 - 4 } & Cimanyar & Ciharus & $\mathrm{R}_{\text {region }}$ & Disch \\
\hline 1 & 2 & 0.09 & 1.47 & 0.00 \\
\hline 2 & 19.5 & 0.92 & 14.34 & 4.96 \\
\hline 3 & 21 & 0.99 & 15.45 & 13.64 \\
\hline 4 & 14 & 0.66 & 10.30 & 12.19 \\
\hline 5 & 2.5 & 0.12 & 1.84 & 13.53 \\
\hline 6 & 0 & 0 & 0.00 & 13.43 \\
\hline 7 & 0 & 0 & 0.00 & 13.33 \\
\hline 8 & 0 & 0 & 0.00 & 12.81 \\
\hline 9 & 0 & 0 & 0.00 & 13.33 \\
\hline 10 & 0 & 0 & 0.00 & 12.29 \\
\hline 11 & 0 & 0 & 0.00 & 11.78 \\
\hline 12 & 0 & 0 & 0.00 & 11.26 \\
\hline 13 & 0 & 0 & 0.00 & 10.74 \\
\hline 14 & 0 & 0 & 0.00 & 10.85 \\
\hline 15 & 0 & 0 & 0.00 & 10.12 \\
\hline 16 & 0 & 0 & 0.00 & 9.40 \\
\hline 17 & 0 & 0 & 0.00 & 8.57 \\
\hline 18 & 0 & 0 & 0.00 & 7.33 \\
\hline 19 & 0 & 0 & 0.00 & 8.99 \\
\hline 20 & 0 & 0 & 0.00 & 9.92 \\
\hline 21 & 0 & 0 & 0.00 & 8.06 \\
\hline 22 & 0 & 0 & 0.00 & 7.13 \\
\hline 23 & 0 & 0 & 0.00 & 2.89 \\
\hline & & & & \\
\hline
\end{tabular}

c. Kejadian Hujan 3 (18 februari 2013)

\begin{tabular}{|c|c|c|c|c|}
\hline \multirow{2}{*}{ Hour } & \multicolumn{3}{|c|}{ Rainfall $(\mathrm{mm})$} & $\begin{array}{c}\text { Observed } \\
\text { Discharge }(\mathrm{m} 3 / \mathrm{s})\end{array}$ \\
\cline { 2 - 4 } & Cimanyar & Ciharus & $\mathrm{R}_{\text {region }}$ & Dinn \\
\hline 1 & 1.50 & 0.09 & 1.11 & 0.00 \\
\hline 2 & 0.50 & 0.03 & 0.37 & 0.40 \\
\hline 3 & 51.00 & 2.92 & 37.66 & 2.37 \\
\hline 4 & 17.00 & 0.97 & 12.55 & 8.67 \\
\hline 5 & 0.00 & 0.00 & 0.00 & 8.36 \\
\hline 6 & 0.00 & 0.00 & 0.00 & 6.81 \\
\hline 7 & 0.00 & 0.00 & 0.00 & 5.15 \\
\hline 8 & 0.00 & 0.00 & 0.00 & 0.00 \\
\hline
\end{tabular}




\section{IV.2 Kalibrasi dan Validasi Model}

Pada pemodelan MIKE SHE, input hujan yang akan dimodelkan berupa intensitas hujan rata-rata wilayah yang didapat dari output analisa hujan yang kemudian dikurangi dengan abstraksi. Input hujan ratarata yang merupakan kejadian hujan tunggal (single event) dapat dilihat pada tabel 1 .

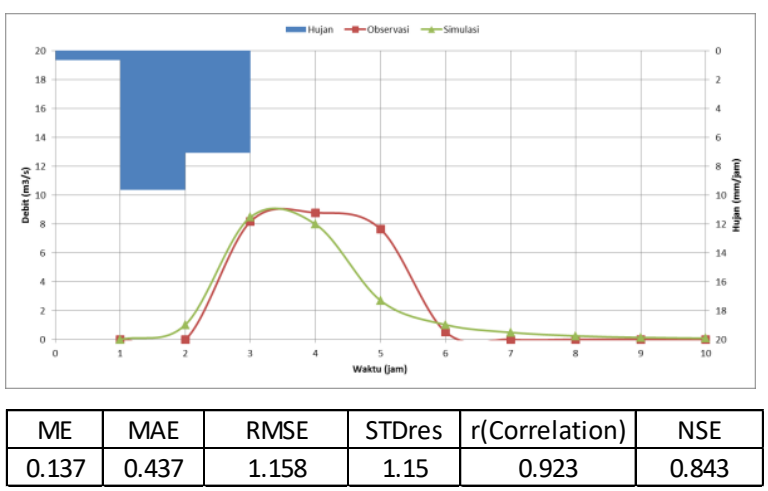

Gambar 3. Hasil kalibrasi kejadian hujan 1

Berdasarkan pemodelan diatas dapat dilihat bahwa debit tertinggi simulasi $\left(8,47 \mathrm{~m}^{3} / \mathrm{s}\right)$ mendekati debit tertinggi observasi $\left(8,78 \mathrm{~m}^{3} / \mathrm{s}\right)$, dengan nilai Koefisien Nash (NSE) sebesar 0,84. Akan tetapi bentuk hidrograf kejadian hujan yang disimulasikan berbeda dengan bentuk hidrograf observasi. Hal ini dikarenakan keterbatasan data yang didapat oleh peneliti. Setelah dilakukan kalibrasi dan dinilai hasilnya cukup bagus, maka tahap selanjutnya dilakukan validasi data. Validasi data ini bertujuan untuk mengukur keberlakuan parameter yang digunakan pada saat kalibrasi.

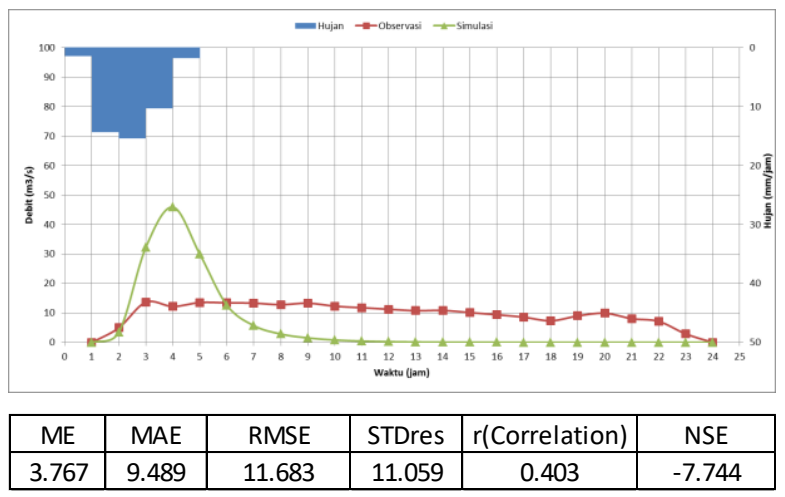

Gambar 4. Hasil validasi kejadian hujan 1 (1)

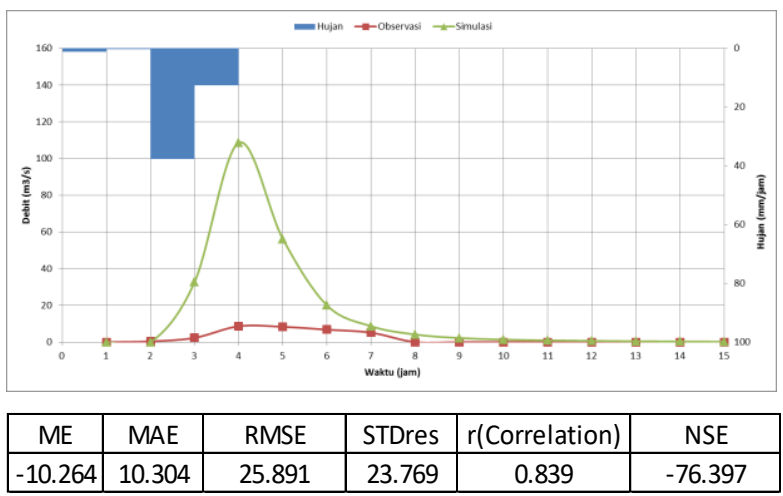

Gambar 5. Hasil validasi kejadian hujan 1 (2)

Berdasarkan hasil pemodelan dapat dapat terlihat bahwa terjadi perbedaan puncak debit yang cukup signifikan, sehingga dapat dikatakan bahwa validasi yang dilakukan tidak cukup bagus. Oleh karena itu peneliti mencoba melakukan kalibrasi kembali dengan memodelkan kejadian hujan 2 (tanggal 27 Oktober 2012).

Pada kejadian hujan 2 ini, pada data debit pengamatan dapat terlihat bahwa kejadian hujan menghasilkan puncak hidrograf yang tidak terlalu tinggi tetapi bentuk hidrograf mengindikasikan adanya aliran interflow.

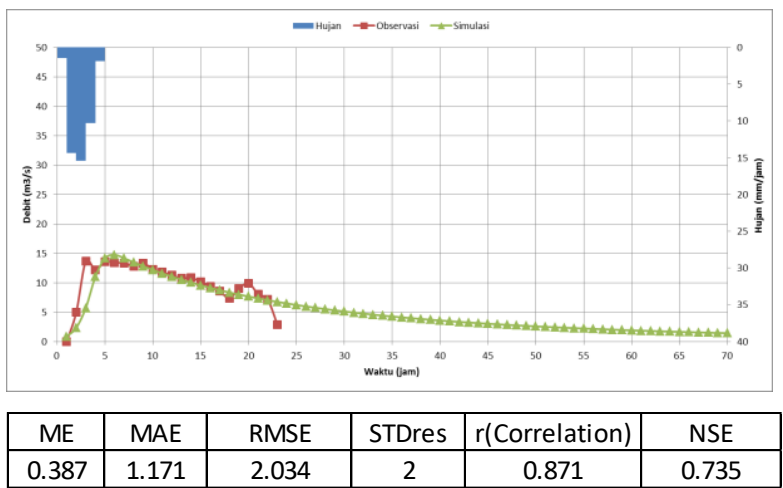

Gambar 6. Hasil validasi kejadian hujan 2

Berdasarkan pemodelan diatas dapat dilihat bahwa debit tertinggi simulasi $(14,74 \mathrm{~m} 3 / \mathrm{s})$ mendekati debit tertinggi observasi $(13,64 \mathrm{~m} 3 / \mathrm{s})$, dengan nilai Koefisien Nash (NSE) sebesar 0,735. 


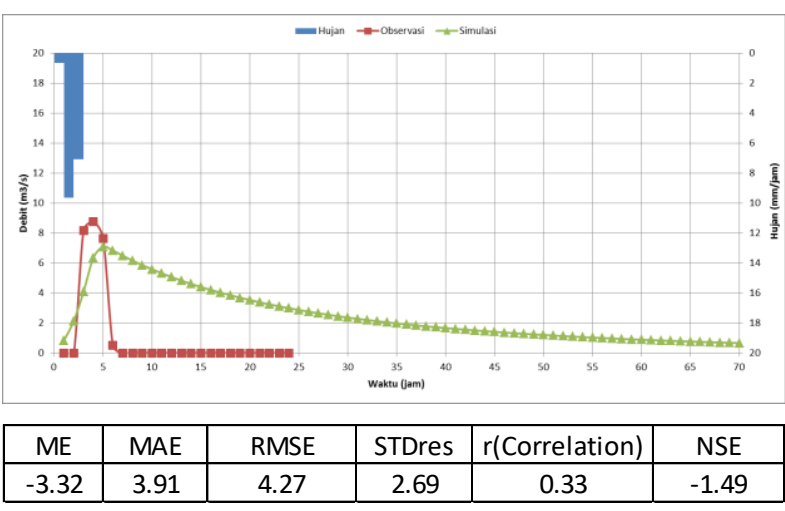

Gambar 7. Hasil validasi kejadian hujan 2 (1)

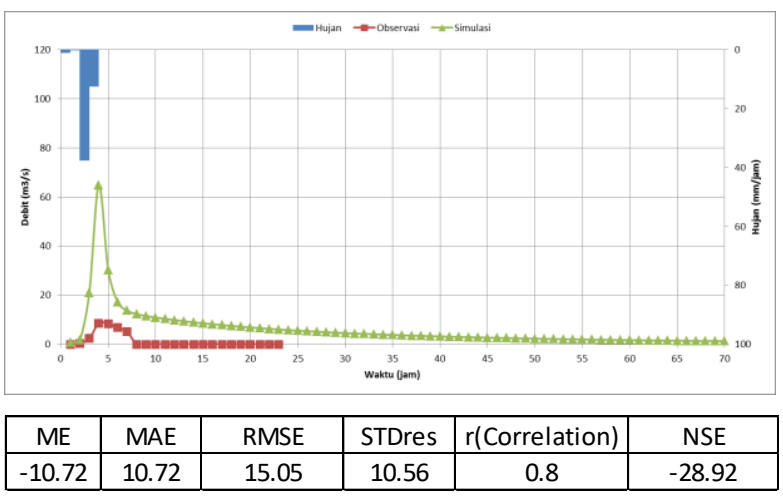

Gambar 8. Hasil validasi kejadian hujan 2 (2)

Dari uji validasi diatas dapat kita ketahui bahwa hasil pemodelan dengan mekanisme aliran interflow yang dilakukan tidak cukup bagus.

Berdasarkan data hidrograf observasi, pada awalnya peneliti menduga adanya mekanisme interflow. Akan tetapi setelah melakukan kalibrasi data dengan kejadian hujan 2, kemudian di validasi dengan kejadian hujan 1 dan 3, dugaan adanya mekanisme interflow tidak terjadi.

Berdasarkan hasil perhitungan dan pemodelan beberapa kejadian hujan, maka dapat dipahami pula bahwa nilai koefisien limpasan dapat berubah-ubah berdasarkan kelembaban tanah, periode waktu dan volume limpasan yang terjadi.

Tabel 2. Nilai Koefisien Limpasan pada Sub-DAS Cimanyar

\begin{tabular}{|c|c|c|c|}
\hline $\begin{array}{c}\text { Even } \\
\text { Hujan }\end{array}$ & Volume Hujan & Volume Limpasan & Koefisien \\
\cline { 2 - 3 } & $(\mathrm{m} 3)$ & $(\mathrm{m} 3)$ & Limpasan \\
\hline 1 & $537,846.04$ & $222,398.28$ & 0.41 \\
\hline 2 & $1,343,307.52$ & $815,532.84$ & 0.61 \\
\hline 3 & $1,714,210.68$ & $113,595.30$ & 0.07 \\
\hline
\end{tabular}

Berdasarkan tabel perhitungan rasio volume limpasan dengan volume hujan diatas, secara volumetrik dapat diketahui bahwa nilai koefisien limpasan pada Sub-DAS Cimanyar berkisar antara 0,07 sampai dengan 0,61 .

\section{KESIMPULAN DAN SARAN}

\section{V.1 Kesimpulan}

1. Kalibrasi pada kejadian hujan pada tanggal 4 Februari 2013 menghasilkan Koefisien Nash sebesar 0,84 . Debit simulasi tertinggi yang terjadi yaitu sebesar $8.47 \mathrm{~m}^{3} / \mathrm{s}$. Sedangkan debit puncak tertinggi hasil pengamatan yaitu sebesar 8,78 $\mathrm{m}^{3} / \mathrm{s}$.

2. Kalibrasi pada kejadian hujan pada tanggal 27 Oktober 2012 menghasilkan Koefisien Nash sebesar 0,74 . Debit simulasi tertinggi yang terjadi yaitu sebesar $14,74 \mathrm{~m}^{3} / \mathrm{s}$. Sedangkan debit puncak tertinggi hasil pengamatan yaitu sebesar 13,64 $\mathrm{m}^{3} / \mathrm{s}$.

3. Berdasarkan data hidrograf observasi, pada awalnya peneliti menduga adanya mekanisme aliran bawah permukaan/interflow. Akan tetapi setelah melakukan kalibrasi data dengan kejadian hujan 2, kemudian di validasi dengan kejadian hujan 1 dan 3, dugaan adanya mekanisme aliran bawah permukaan/interflow tidak terjadi.

4. Berdasarkan perhitungan rasio volume limpasan dengan volume hujan yang dilakukan, secara volumetrik dapat diketahui bahwa nilai koefisien limpasan pada Sub-DAS Cimanyar berkisar antara 0,07 sampai dengan 0,61. Berdasarkan hasil perhitungan dan pemodelan beberapa kejadian hujan, maka dapat dipahami pula bahwa nilai koefisien limpasan dapat berubah-ubah berdasarkan kelembaban tanah, periode waktu dan volume limpasan yang terjadi.

\section{V.2 Saran}

1. Dalam mengambil kejadian hujan-debit untuk dianalisa, data pengukuran hujan ataupun debit pada beberapa kejadian mengalami kekosongan. Padahal pada saat itu bisa jadi hujan atau debit yang tercatat di stasiun pengukuran cukup tinggi. Disarankan setiap stasiun hujan atau debit di Indonesia perlu dipelihara dengan baik, sehingga saat terjadi hujan besar/badai tetap bisa beroperasi secara maksimal.

2. Proses validasi membutuhkan data yang cukup banyak agar karakteristik DAS pada model dapat tergambar secara nyata.

3. 


\section{UCAPAN TERIMA KASIH}

Ucapan terima kasih penulis sampaikan kepada Bapak Prof. Ir. Iwan Kridasantausa, M.Sc., Ph.D. dan bapak Hadi Kardhana, S.T., M.T., Ph.D. selaku pembimbing yang telah bersedia meluangkan waktu dan mencurahkan tenaga serta pikirannya selama proses penelitian ini, Mirwan Rofiq Ginanjar, S.T., MPSDA. dan Randy Esa S.Kom. atas dukungan fasilitas data yang diberikan.

\section{REFERENSI}

Chow, Van Te, Maidment, David R., Mays, Larry W. 1988. Applied Hodrology, McGraw-Hill International Editions, Singapore

DHI Software. 2014. MIKE SHE User Guide

DHI Software. 2014. MIKE SHE Reference Guide

DHI Software, 2014, MIKE 11 Reference Guide

Indarto. 2010. Hidrologi Dasar Teori dan Contoh Aplikasi Model Hidrologi, Bumi Aksara, Jakarta

Tanika, Lisa. 2013. Dampak Perubahan Tutupan Lahan Dan Iklim Terhadap Fungsi Hidrologi Daerah Aliran Sungai Konaweha Hulu, Jurnal Sumber Daya Air, Puslitbang Sumber Daya Air, Bandung 